University of Nebraska - Lincoln

DigitalCommons@University of Nebraska - Lincoln

Faculty Publications, UNL Libraries

Libraries at University of Nebraska-Lincoln

$1-29-1989$

\title{
Silica Exposure and Silicosis among Ontario Hardrock Miners: III. Analysis and Risk Estimates
}

D. C. F. Muir

Occupational Health Program, McMaster University, Hamilton, Ontario

J. A. Julian

Occupational Health Program, McMaster University, Hamilton, Ontario

H. S. Shannon

Occupational Health Program, McMaster University, Hamilton, Ontario, shannonh@mcmaster.ca

D. K. Verma

Occupational Health Program, McMaster University, Hamilton, Ontario, vermadk@mcmaster.ca

A. Sebestyen

Occupational Health Program, McMaster University, Hamilton, Ontario

See next page for additional authors

Follow this and additional works at: https://digitalcommons.unl.edu/libraryscience

Part of the Library and Information Science Commons

Muir, D. C. F.; Julian, J. A.; Shannon, H. S.; Verma, D. K.; Sebestyen, A.; and Bernholz, Charles D., "Silica Exposure and Silicosis among Ontario Hardrock Miners: III. Analysis and Risk Estimates" (1989). Faculty Publications, UNL Libraries. 104.

https://digitalcommons.unl.edu/libraryscience/104

This Article is brought to you for free and open access by the Libraries at University of Nebraska-Lincoln at DigitalCommons@University of Nebraska - Lincoln. It has been accepted for inclusion in Faculty Publications, UNL Libraries by an authorized administrator of DigitalCommons@University of Nebraska - Lincoln. 


\section{Authors}

D. C. F. Muir, J. A. Julian, H. S. Shannon, D. K. Verma, A. Sebestyen, and Charles D. Bernholz 


\title{
Silica Exposure and Silicosis among Ontario Hardrock Miners: III. Analysis and Risk Estimates
}

\author{
D. C. F. Muir, PhD, FRCP, J. A. Julian, MMath, H. S. Shannon, PhD, \\ D. K. Verma, PhD, CIH, A. Sebestyen, BSc, and C. D. Bernholz, MA \\ Occupational Health Program, McMaster University, Hamilton, Ontario, Canada
}

Accepted for publication December 12, 1988.

\begin{abstract}
An epidemiological investigation was undertaken to determine the relationship between silicosis in hardrock miners in Ontario and cumulative exposure to silica (free crystalline silica — $\alpha$ quartz) dust. This report describes the analytic method and presents the risk estimates.
\end{abstract}

Key words: silica, konimeter, dose-response, respirable dust, pneumoconiosis

\section{INTRODUCTION}

The basic methodology of this survey has been described in parts I and II of this series of reports [Muir et al., 1989; Verma et al., 1989]. Of miners who joined the hardrock mining industry in Ontario between 1940 and 1959, data from 2,109 who met the criteria for inclusion in this study were examined to determine the incidence of silicosis in relation to cumulative respirable silica exposure. A diagnosis of silicosis was made on the appearance of radiological category $1 / 1$ or greater with round opacities, as classified by the ILO [1980] method. The films were independently classified by five readers.

\section{RESULTS AND ANALYSIS}

The length of follow-up for miners entering the survey at different ages is shown in Figure 1. There appeared to be little evidence that duration of employment was related to age at entry except for those aged 40 or more. In Figure 2, cumulative respirable silica exposure is related to years of employment. The results suggest that low cumulative exposure tended to be a result of relatively short duration of employment. For higher categories of cumulative exposure, there was no evidence of a relationship to years of exposure. The implication of this is that miners with high cumulative exposures were employed in dusty areas rather than that they spent long periods in the industry.

Table I shows the 32 cases of silicosis, as identified by each reader, as well as the 


\section{YEARS OF FOLLOW-UP}

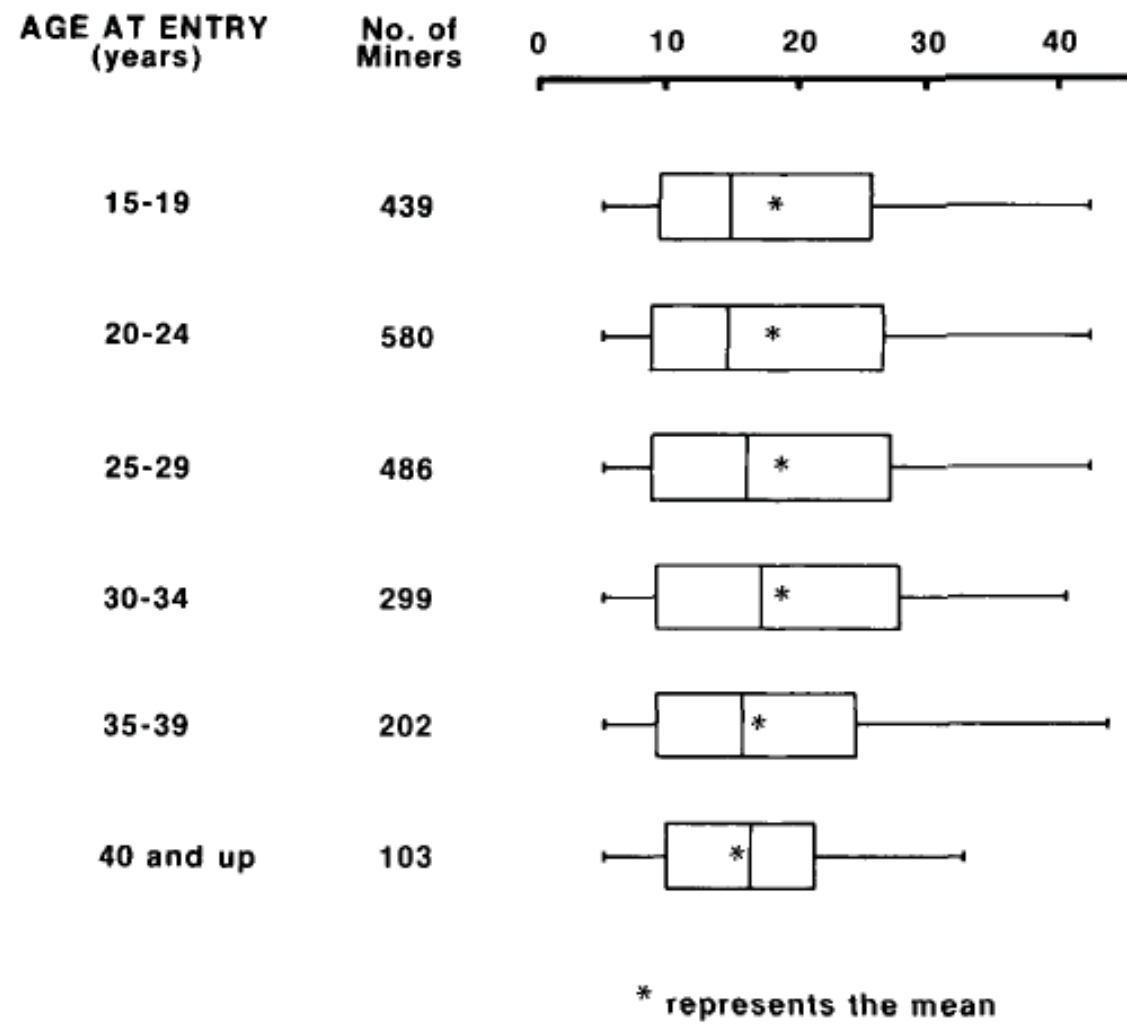

Fig. 1. Boxplots of years of follow-up for 2,109 Ontario hardrock miners by age at entry showing the mean, quartiles, and range.

elapsed time since first exposure and the corresponding age at diagnosis. Where one or more readers identified a case, it should not be assumed that the other readers considered the film to be normal. These readers may have observed opacities but considered them either to be category $1 / 0$ or less, to be of the irregular $(s, t, u)$ variety rather than round, or not to be characteristic of pneumoconiosis.

Table I illustrates differences between the readers in the number of cases which they identified as having silicosis. Such interreader variability is well recognized and has been described in part I of this series of reports [Muir et al., 1989].

\section{STATISTICAL ANALYSIS}

A number of assumptions are germane to our choice of analysis. First, silicosis is treated as a disease that is acquired through exposure to silica dust. That is, there is no risk if there is no exposure. Second, we have taken no account of possible disease progression after exposure ceases. Third, it is the accumulation of silica over the years, and not the rate of exposure, that is the important factor.

A method of analysis suitable under these assumptions is survival analysis with censoring treating the cumulative dose of respirable silica as the continuum instead of time. 


\section{CUMULATIVE \\ EXPOSURE \\ (mg/m ${ }^{3}$-years)}

0-0.499

0.5-0.999

1.0-1.499

1.5-1.999

2.0 and up

\section{No. of \\ Miners}

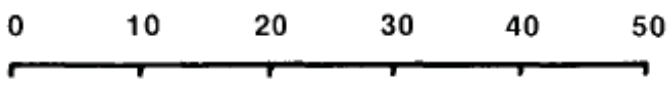

1313

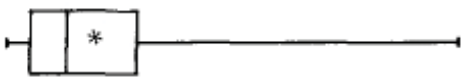

582

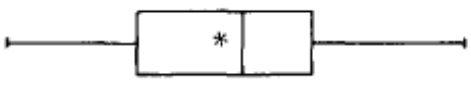

103

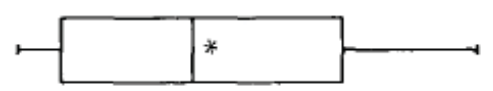

48

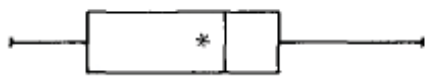

63

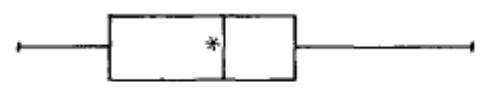

* represents the mean

Fig. 2. Boxplots of years of dust exposure for 2,109 Ontario hardrock miners by cumulative exposure showing the mean, median, and range.

Furthermore, since it is generally accepted that there is a delay between the time of deposition of silica in the lungs and the appearance of silicosis, lagging of exposure was considered. Analysis was conducted by using 0-, 2-, and 5-year lags. Therefore, for each case, the cumulative dose up to the time of diagnosis or the time he left the industry was calculated less the dose accumulated during the last 0,2 , or 5 years. For the silicotics, there was a separate response for each of the five readers.

Because of the low frequency of silicotics in this study, parametric failure-time models were fitted and appropriate confidence intervals were estimated. Typically, the accelerated failure-time class of models based on the generalized gamma family is employed for human populations [Lawless, 1982]. This family includes the exponential, Weibull, lognormal, log-logistic, and gamma distributions and their log counterparts. By using maximum likelihood, parameters are estimated, and the best-fitting model can be selected by comparison with other family members in the hierarchy. By-products of this method are estimates of the standard errors of the parameter estimates. Therefore, confidence intervals for the response, the lagged cumulative dose, and the cumulative risk can be estimated.

A complication with these data is the multiplicity of responses, one reading for each of five readers. Since all readers assessed the X-rays independently, we can analyze the responses separately or we can generate a consensus response based on agreement of diagnosis (but not date of onset). For example, a three-reader consensus would classify a miner as silicotic if three or more responses were abnormal, and the date of diagnosis would be set at the earliest classification date. 
TABLE I. Type of Mining Experience, Years Since First Exposure, and Age at Diagnosis for Each Case by X-Ray Reader*

\begin{tabular}{|c|c|c|c|c|c|c|}
\hline \multirow[b]{2}{*}{ Case } & \multirow[b]{2}{*}{ Type } & \multicolumn{5}{|c|}{ Years since first exposure (age at diagnosis) } \\
\hline & & $\begin{array}{c}\text { Reader } \\
1\end{array}$ & $\begin{array}{c}\text { Reader } \\
2\end{array}$ & $\begin{array}{c}\text { Reader } \\
3 \\
\end{array}$ & $\begin{array}{c}\text { Reader } \\
4\end{array}$ & $\begin{array}{c}\text { Reader } \\
5\end{array}$ \\
\hline 1 & Uranium & & $15(46)$ & $15(46)$ & $18(49)$ & \\
\hline 2 & Uranium & & & $18(44)$ & & \\
\hline 3 & Uranium & $16(38)$ & $13(35)$ & $14(36)$ & $15(37)$ & $16(38)$ \\
\hline 4 & Uranium & $13(44)$ & $12(43)$ & $10(41)$ & $10(41)$ & $13(44)$ \\
\hline 5 & Gold & $35(62)$ & $34(61)$ & $34(61)$ & $33(60)$ & $34(61)$ \\
\hline 6 & Gold & $28(59)$ & $28(59)$ & & & \\
\hline 7 & Gold & & $31(58)$ & & & \\
\hline 8 & Gold & $35(61)$ & $34(60)$ & $31(57)$ & $34(60)$ & \\
\hline 9 & Gold & $36(55)$ & $31(50)$ & $37(56)$ & $35(54)$ & $37(56)$ \\
\hline 10 & Gold & $38(57)$ & & $37(56)$ & $38(57)$ & \\
\hline 11 & Gold & & & & $25(56)$ & \\
\hline 12 & Gold & $9(38)$ & & & & \\
\hline 13 & Gold & & $30(64)$ & $27(61)$ & & \\
\hline 14 & Gold & $29(63)$ & $28(62)$ & $27(61)$ & & \\
\hline 15 & Gold & & $27(51)$ & $28(52)$ & $30(54)$ & \\
\hline 16 & Gold & & & $31(59)$ & & \\
\hline 17 & Gold & & $23(53)$ & & & \\
\hline 18 & Gold & $26(64)$ & $23(61)$ & $22(60)$ & $25(63)$ & \\
\hline 19 & Gold & & $16(44)$ & & & \\
\hline 20 & Gold & & $25(58)$ & $27(60)$ & & \\
\hline 21 & Gold & & & $28(48)$ & & \\
\hline 22 & Mixed & $26(46)$ & $25(45)$ & $23(43)$ & $25(45)$ & $26(46)$ \\
\hline 23 & Mixed & $22(44)$ & $19(41)$ & $21(43)$ & $20(42)$ & $21(43)$ \\
\hline 24 & Mixed & & $15(37)$ & $21(43)$ & & \\
\hline 25 & Mixed & $37(64)$ & $36(63)$ & $36(63)$ & & \\
\hline 26 & Mixed & & & $33(57)$ & & \\
\hline 27 & Mixed & & $29(48)$ & $33(52)$ & & \\
\hline 28 & Mixed & $30(59)$ & $26(55)$ & $30(59)$ & $24(53)$ & \\
\hline 29 & Mixed & & $28(46)$ & & & \\
\hline 30 & Mixed & & $28(62)$ & & & \\
\hline 31 & Mixed & & & $32(53)$ & & \\
\hline 32 & Mixed & & $15(39)$ & $12(36)$ & $17(41)$ & $17(41)$ \\
\hline
\end{tabular}

*Case defined by each reader as round opacities, $1 / 1$ or greater.

\section{RESULTS}

All ten response sets, five individual responses and five consensus responses, were analyzed by using the SAS LIFEREG procedure for fitting generalized gamma survival distributions. Based on the assessment of the mean, scale, and shape parameters and the log likelihood values, the Weibull model appears best suited to the ten sets. The cumulative risk can then be modeled as

$$
\mathrm{R}(\mathrm{x})=\exp \left[-(\alpha \mathrm{x})^{\beta}\right], \mathrm{x} \geq 0, \beta>0
$$

where $\mathrm{R}=$ cumulative risk, $\mathrm{x}=$ cumulative lagged dose, $\alpha=$ Weibull scale parameter, and $\beta=$ Weibull shape parameter. 
TABLE II. Parameter Estimates and 95\% Confidence Intervals for the Weibull Cumulative Dose-Cumulative Risk Model for Each Reader*

\begin{tabular}{lccccc}
\hline & \multicolumn{2}{c}{ Scale parameter $\alpha$} & & \multicolumn{2}{c}{ Shape Parameter $\beta$} \\
\cline { 2 - 3 } \cline { 5 - 6 } Reader & Estimates & $95 \% \mathrm{CI}$ & & Estimate & $95 \%$ CI \\
\hline 1 & 92.8 & $31.8-270.4$ & & 1.41 & $1.03-2.22$ \\
2 & 41.7 & $22.4-76.7$ & & 1.67 & $1.32-2.27$ \\
3 & 31.5 & $19.5-50.9$ & & 1.96 & $1.54-2.70$ \\
4 & 58.0 & $23.8-141.2$ & & 1.67 & $1.41-2.04$ \\
5 & 46.1 & $17.8-119.1$ & & 2.22 & $1.54-4.00$ \\
\hline
\end{tabular}

*Based on the extreme value distribution of the logarithm of cumulative dose.

The 0-, 2-, and 5-year lagged cumulative dose estimates were also assessed using maximum likelihood. The 5-year lag consistently provided the best fit (i.e., largest log likelihood value). The parameter estimates along with their $95 \%$ confidence intervals are shown in Table 11.

The product-limit estimates [Kaplan and Meier, 1958] along with the fitted Weibull models for each of the five readers are displayed in Figures 3-7. Although there are few events, the models appear to fit the data extremely well. The five individual reader curves are superimposed in Figure 8. To illustrate the effect of the various consensus combinations, Figure 9 shows the fitted Weibull curves by using all the data ranging from any reader agreement to 5 (all) reader agreement. For these consensus combinations, the initial date at which any of the readers identified category $1 / 1$ silicosis or greater was taken as the time of diagnosis for analytic purposes.

Cumulative risk estimates for various intensities of respirable silica exposure, based on 40 years of exposure, are shown in Table III together with confidence intervals calculated according to the method described by Nelson [1982]. Table IV shows similar calculations expressing the cumulative respirable silica exposures associated with various risks.

\section{DISCUSSION}

In this study, there were few cases of silicosis diagnosed by the readers. Variability between readers further complicated the analysis. Where more than one reader classifies films, it is common practice to treat the classifications, which are categorical, as if they were continuous and the categories as if of equal width. With these assumptions, an arithmetic mean of the classifications of a single film by different readers can be calculated. These assumptions have not been validated for the case of silicosis. In the present study, the objective was rather to identify the point at which each reader considered silicosis at the $1 / 1$ category or greater to be present. The method has clinical relevance in the sense that data from each reader respond to the question, "Does this individual have silicosis?" This binary response is suitable for analysis by survival curve methods and particularly so when the number of data points is restricted. The validity of this method for handling environmental exposures [Berry et al., 1979; Finkelstein, 1985] is conditional upon the assumption that the radiographic changes are specifically the result of dust exposure and could not be random or unrelated events. 


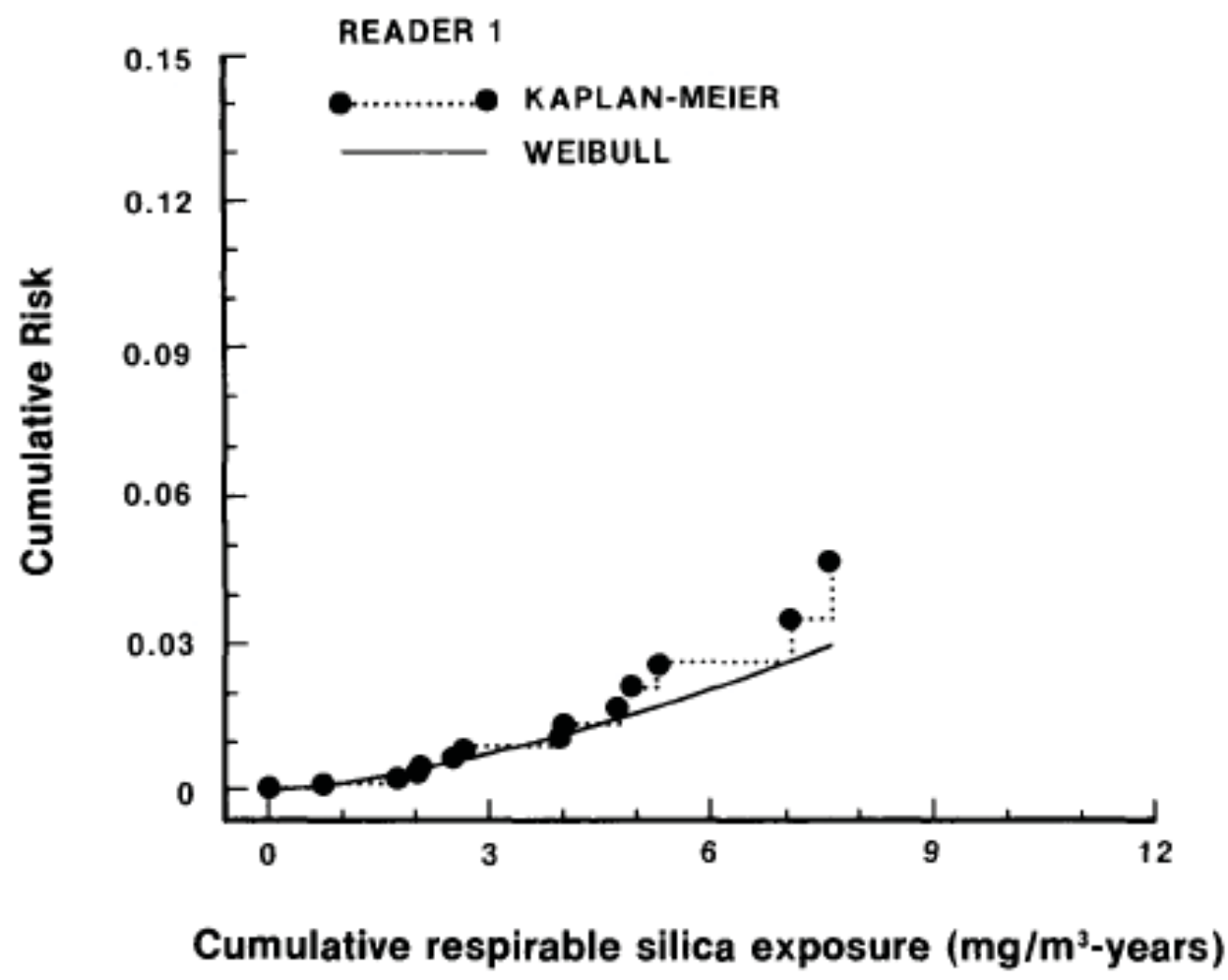

Fig. 3. Kaplan-Meier and fitted Weibull survival curves showing the estimated cumulative risk of silicosis as a function of cumulative respirable silica exposure $\left(\mathrm{mg} / \mathrm{m}^{3}\right.$ years) lagged 5 years for reader 1 .

This assumption may invalidate attempts to determine whether cumulative gravimetric respirable silica estimates are a better measure of the health risk than cumulative konimeter counts. Such a comparison of two different methods of measuring exposure has been undertaken in the British coal-mining industry. In coal mines, particle counts of airborne dust obtained with a thermal precipitator correlated poorly with the progression of pneumoconiosis of coal workers. Much improved correlations were obtained by the use of gravimetric respirable dust exposure measurements (W. H. Walton, personal communication). The improved correlations furnished independent evidence that cumulative respirable dust was a better measure of the health risk in coal mining.

Our data do not provide a method of identifying the "best" reader. Figures 3-7 clearly show that there were differences between the number of silicotic cases identified by each physician and in the corresponding risk associated with any given level of cumulative silica exposure. This may reflect not only differing levels of reader sensitivity in evaluating the degree of pneumoconiosis but also that some readers could be misclassifying abnormalities which were not the result of dust exposure. It should be noted that the instructions for the use of the ILO classification require that the reader make an initial judgment as to whether the radiographic changes are compatible with pneumoconiosis. We have no external standard (such as tissue histology) to test the hypothesis that false-positive diagnoses were made by some readers or that false-negatives were made by others. 


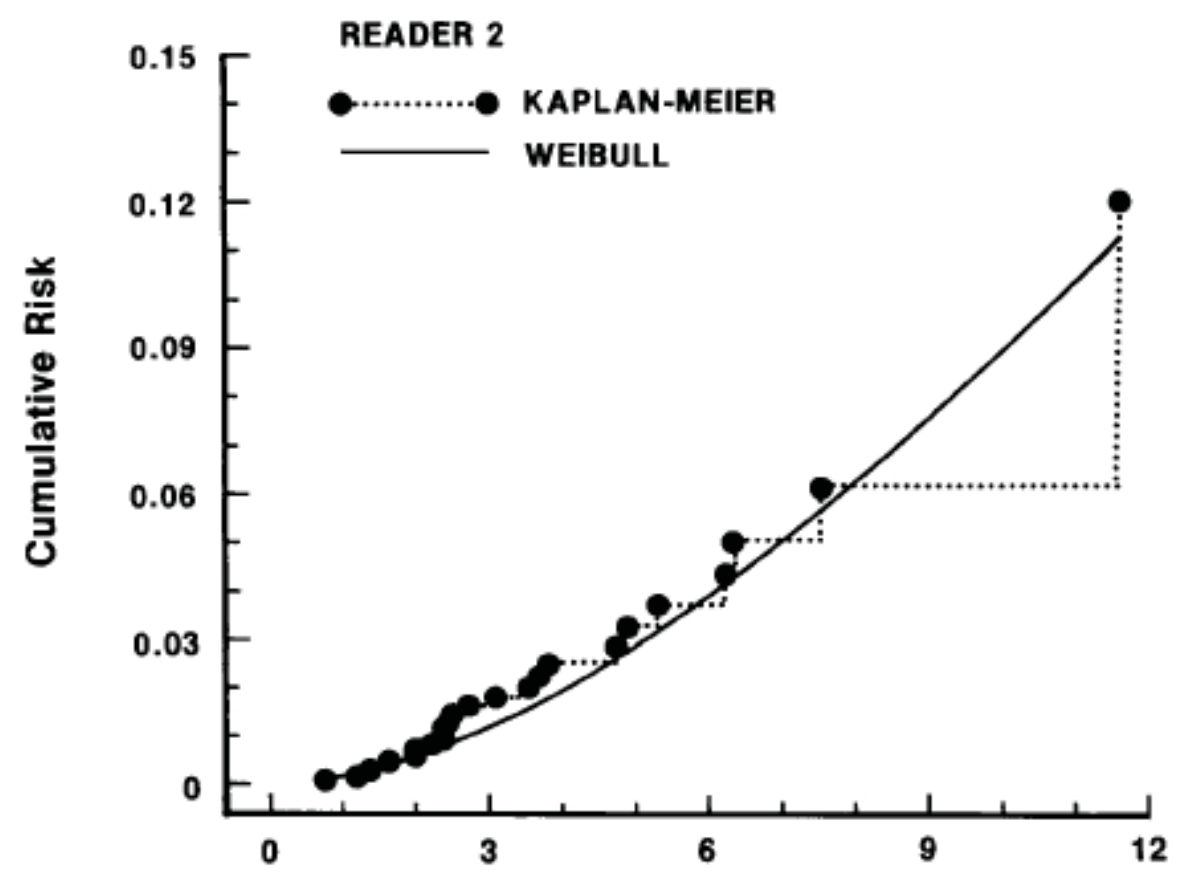

\section{Cumulative respirable silica exposure $\left(\mathrm{mg} / \mathrm{m}^{3}\right.$-years $)$}

Fig. 4. Kaplan-Meier and fitted Weibull survival curves showing the estimated cumulative risk of silicosis as a function of cumulative respirable silica exposure $\left(\mathrm{mg} / \mathrm{m}^{3}\right.$ years $)$ lagged 5 years for reader 2 .

To this extent, the radiographic diagnoses must be regarded as subjective and the final result as representing the overall opinions of five readers working in strict independence. A median value of the five separate estimates of risk may be the best overall value for control purposes.

In comparing the values reported in this study with those of other investigations, it is apparent that the literature contains relatively few epidemiological surveys of silicosis. Certain confounding variables must be considered. First, it seems likely that some forms of crystalline silica such as cristobalite and tridymite have a greater fibrogenic potential than silica itself. This was demonstrated in animal experiments by Gardner [1938] and King et al. [1953a]. For this reason, the epidemiological surveys of Fulton et al. [1939] in the silica brick industry and by Cooper and Cralley [1958] in workers exposed to calcined diatomite cannot be compared to the present data since the airborne dust in their studies contained very high proportions of both cristobalite and tridymite. Similarly, it appears that silica mixed with very high concentrations of inert coal dust and silicates may reduce the apparent toxicity of the silica fraction. Walton et al. [1977] could not detect an independent silica effect on the progression of pneumoconiosis of coal miners when the fractional concentration of silica in the respirable dust was below about $12 \%$, despite relatively high absolute airborne silica concentrations. There is also some evidence that the composition of the other minerals in the airborne dust may be important. For example, Rajhans and Budlovsky [1972] found no evidence of silicosis in the brick industry in Ontario 


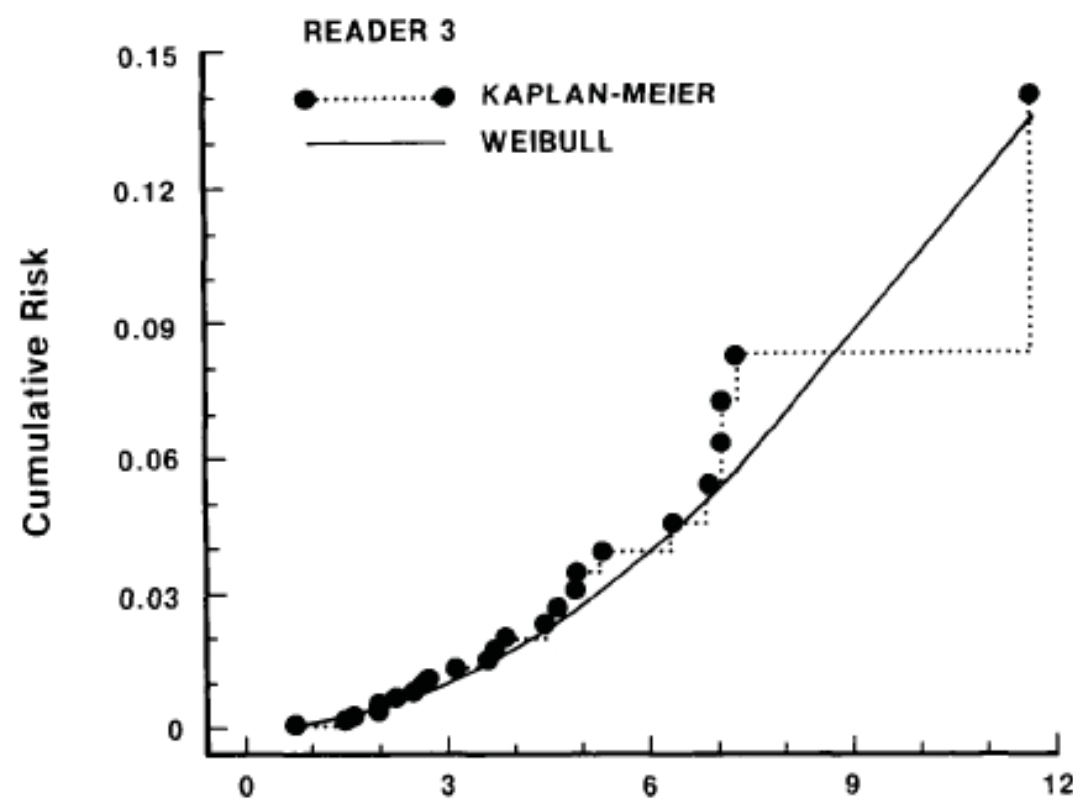

Cumulative respirable silica exposure $\left(\mathrm{mg} / \mathrm{m}^{3}\right.$-years $)$

Fig. 5. Kaplan-Meier and fitted Weibull survival curves showing the estimated cumulative risk of silicosis as a function of cumulative respirable silica exposure $\left(\mathrm{mg} / \mathrm{m}^{3}\right.$ years) lagged 5 years for reader 3 .

and suggested that this might be because of the high concentrations of clay minerals in the dust. In this context, it should be noted that many of the miners in our investigation had inhaled finely divided aluminum dust prior to underground work since this was thought to be a prophylactic measure. Finally, it is possible that respirable dust containing a high proportion of very small silica particles may present a special hazard [King et al., 1953b]. For these reasons, it is important to use caution when comparing risks in one industry or process with those found in other situations.

The granite quarries and associated workplaces at Barre, Vermont, have been the subject of many epidemiological surveys and provide the basic information on which current silica control levels in many countries are based. Dust levels in the industry were very high in the early years of this century, and more than $90 \%$ of the workers examined in 1920 were reported to have silicosis in a classic study of the industry [Russell et al., 1929]. This led to the introduction of dust control measures in 1937 which were applied to all workplaces in the industry by 1940. By 1964, Ashe and Bergstrom [Ashe and Bergstrom, 1964] were able to report on the virtual elimination of silicosis. An important series of investigations in the Vermont granite industry was published by Thériault and colleagues [1974a,b]. The investigations consisted of a cross-sectional survey of 880 men aged between 25 and 65 who were currently working in the granite sheds. Radiographs were obtained on 784 men and were read by a single reader; 551 were classified as normal and 233 as category 1 or greater on the ILO [1972] scale; 67 films were classified as showing irregular opacities; and 166 were classified as round. No comment is not- 


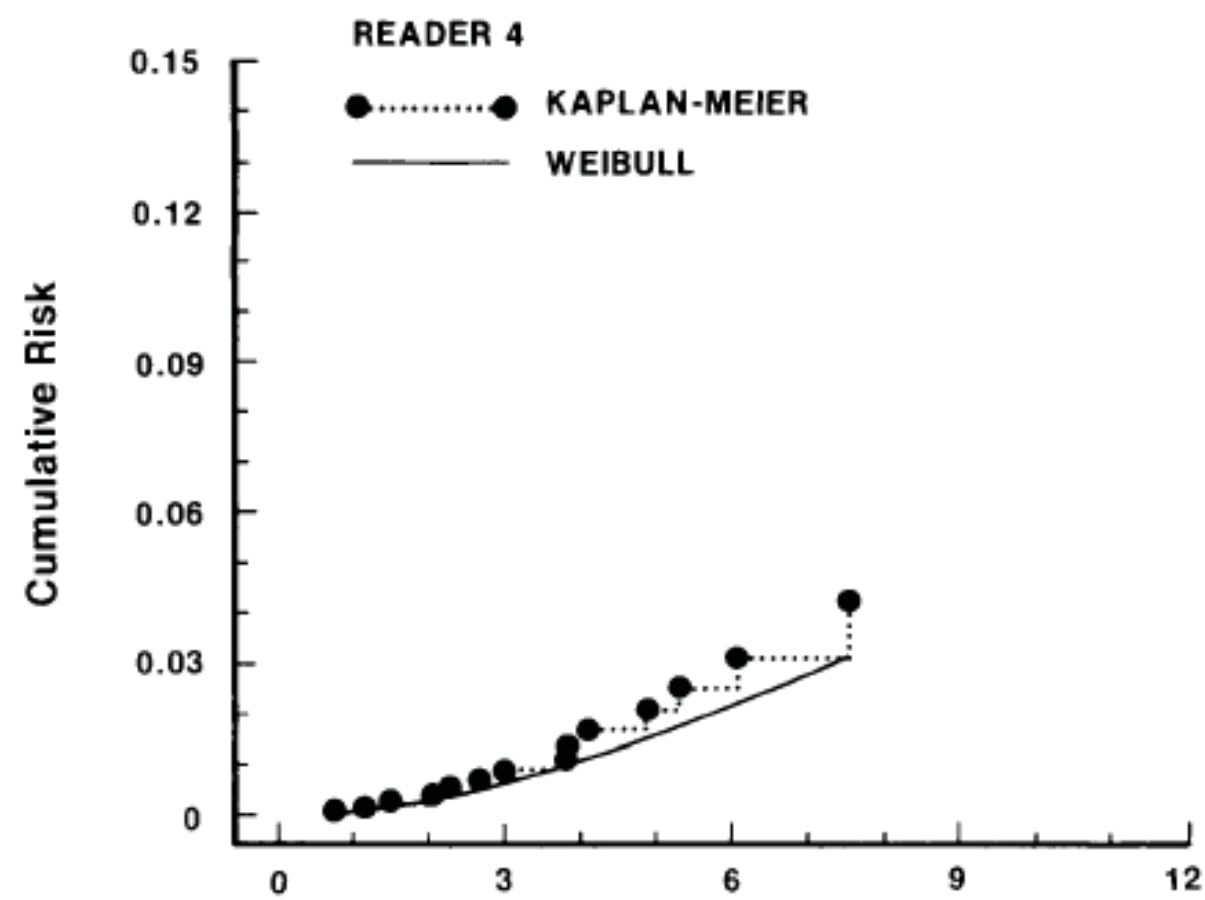

\section{Cumulative respirable silica exposure $\left(\mathrm{mg} / \mathrm{m}^{3}\right.$-years $)$}

Fig. 6. Kaplan-Meier and fitted Weibull survival curves showing the estimated cumulative risk of silicosis as a function of cumulative respirable silica exposure $\left(\mathrm{mg} / \mathrm{m}^{3}\right.$ years) lagged 5 years for reader 4 .

ed on the proportion, if any, of films showing both types. Cumulative dust exposures up to the date of the radiograph were calculated for each worker and expressed as the number of years of exposure at an equivalent average respirable silica exposure of $50 \mu \mathrm{g} / \mathrm{m}^{3}$. The fractional silica concentration of the respirable dust was about $9 \%$ in more recent years and $13-17 \%$ in the early years. Conversion factors [Ayer et al., 1973] were used to convert early dust measurements carried out with impingers into gravimetric respirable silica equivalents. Irregular radiographic opacities were found to be related to age but not to cumulative dust exposure while round opacities correlated with increasing dust exposure. In presenting the data in terms of the probability that a worker would develop silicosis after varying amounts of cumulative silica exposure, the two sets of abnormalities were combined. This may be one explanation for the somewhat unexpected finding that nearly $30 \%$ of the films appeared to be abnormal at zero dust exposure. For a mean exposure of 0.05 $\mathrm{mg} / \mathrm{m}^{3}$ respirable silica, the probability of developing category 1 abnormalities or greater appeared to be about 50\% after 46 years of work. However, since 67 (39\%) of the abnormal films showed irregular opacities and since these were not correlated with dust exposure, it might provide some estimate of the true dust effect to assume that the films with irregular opacities were randomly distributed in each dust category. On this basis, the true probability of developing category 1 pneumoconiosis after 46 years of exposure to 0.05 $\mathrm{mg} / \mathrm{m}^{3}$ of respirable silica might be about $30 \%$. 


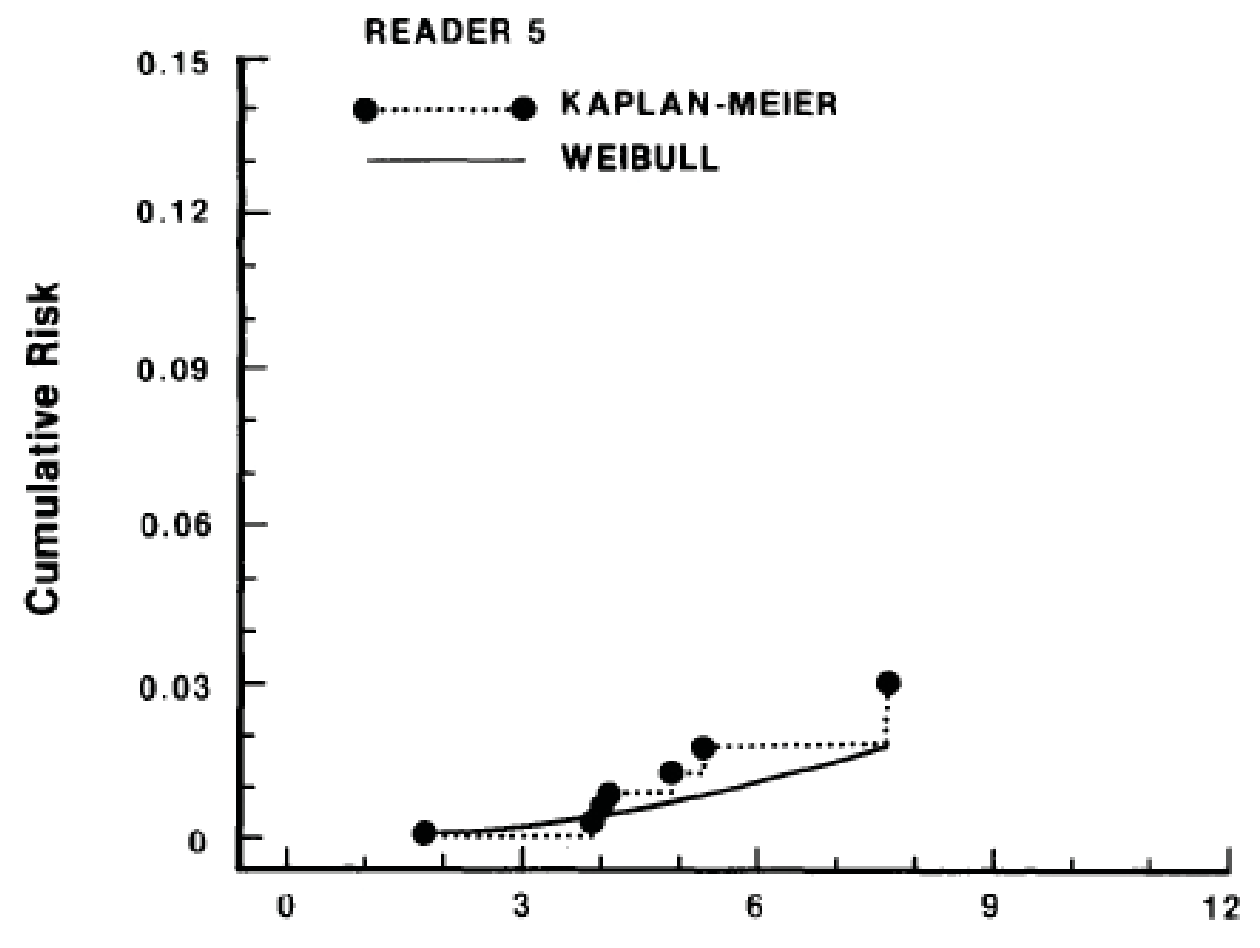

\section{Cumulative respirable silica exposure $\left(\mathrm{mg} / \mathrm{m}^{3}\right.$-years)}

Fig. 7. Kaplan-Meier and fitted Weibull survival curves showing the estimated cumulative risk of silicosis as a function of cumulative respirable silica exposure $\left(\mathrm{mg} / \mathrm{m}^{3}\right.$ years) lagged 5 years for reader 5 .

In the South African goldfields, Beadle [1967] reported an inception cohort study on the prevalence of silicosis in white miners who started work between January 1934 and December 1938 and who completed over 3,000 underground shifts. Among 1,186 miners followed to the end of 1964, $199(17 \%)$ had developed silicosis. It appeared that nearly $36 \%$ of the miners would develop silicosis after 30 years of underground work at a mean dust exposure of about 160 particles per cubic centimeter (ppcc) as measured by a thermal precipitator. Comparison of these results with the present study are not easy since the diagnosis of silicosis depended not only on the radiological appearances but also on disability (not specified). Conversion data for thermal precipitator counts to gravimetric silica are not available, and there is no information on the prevalence of silicosis in miners who did not complete 3,000 shifts and who were thereby excluded from the study. However, a thermal precipitator dust count of 160 ppcc would generally be regarded as fairly low and yet appears to be associated with a high risk of developing silicosis after 30 years of work. The fractional concentration of silica in the respirable dust was not stated.

In male workers in the pottery industry in Britain, Fox et al. [1975] found that the risk of developing category 2 pneumoconiosis or greater after 14.7 years of exposure was about $5 \%$ at a mean respirable silica concentration of $0.1 \mathrm{mg} / \mathrm{m}^{3}$ and $4 \%$ at $0.05 \mathrm{mg} / \mathrm{m}^{3}$. However, extrapolation to zero concentration suggested that the risk was about $3 \%$. This 


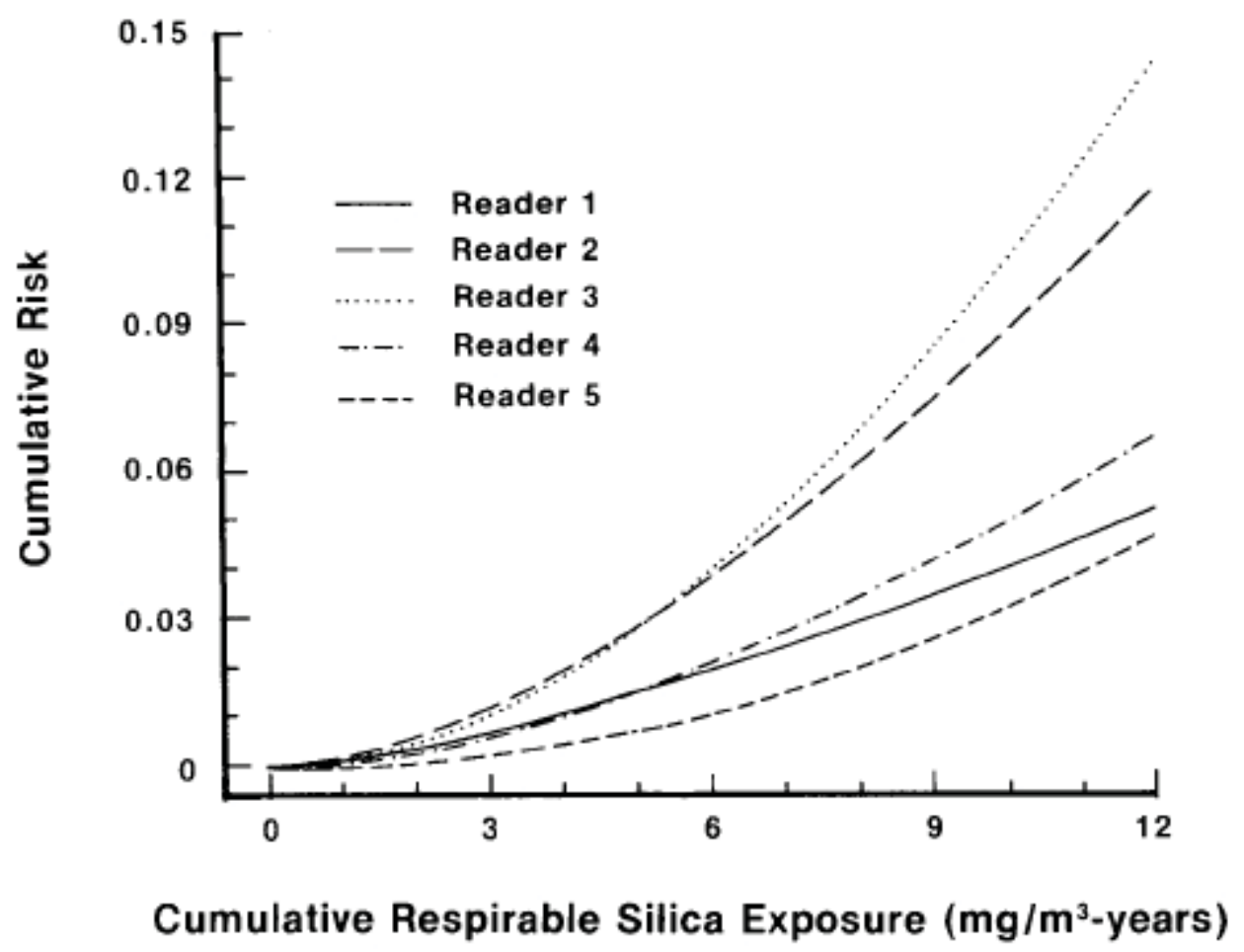

Fig. 8. Fitted Weibull models for each reader showing the relationship between cumulative risk of silicosis and cumulative respirable silica exposure $\left(\mathrm{mg} / \mathrm{m}^{3}\right.$ years $)$ lagged 5 years.

While direct comparisons with the present study are not easy because of different diagnostic criteria, our data suggest lower risk estimates than these previous reports.

Certain features of our investigation may be regarded as under- or overestimating the risks. In the first instance, we studied miners who remained "in view" up to the date of the last radiograph. In some instances, this included a period after leaving the industry, but we have no information on the probability that radiographic changes appeared after that date. Clinical experience suggests that this is uncommon, although it can occur. In a subsequent study, it would be valuable to follow the cohort so that the incidence of silicosis can be measured in men who left the industry at a time when their radiographs were normal. The appearance of disease in miners after leaving the industry would increase the risk estimates, as would another factor concerned with the manner in which the konimeter counts were obtained. In the early years, these were often taken for the purposes of engineering control. As such, they were taken at a time when local dust levels were thought to be high and thus may overestimate an individual miner's average exposure, which, in turn, underestimates the risk.

A potential bias that may lead to an overestimate of the risk associated with a given level of silica is the absence of films corresponding to the "exact" date at which the $1 / 1$ category was reached. This is not felt to be a major problem since the gap was always less 


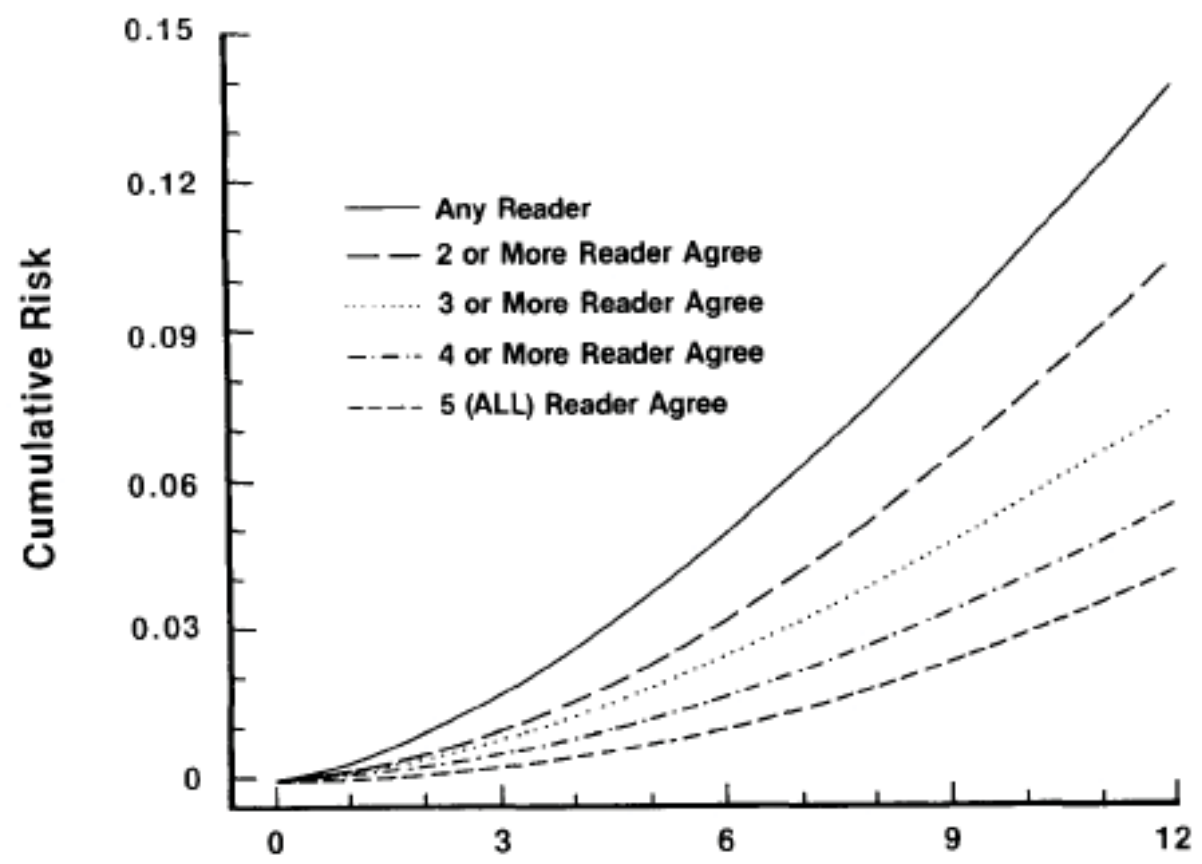

\section{Cumulative Respirable Silica Exposure (mg/m³-years)}

Fig. 9. Fitted Weibull models for various levels of reader consensus showing the relationship between cumulative risk of silicosis and cumulative respirable silica exposure $\left(\mathrm{mg} / \mathrm{m}^{3}\right.$ years) lagged 5 years.

TABLE III. Cumulative Risk Estimates (Percent) of Developing Silicosis and 95\% Confidence Intervals for Four Levels of Mean Respirable Silica Exposure $\left(\mathrm{mg} / \mathrm{m}^{3}\right)$ by Reader(s), Based on 40 Years Exposure*

\begin{tabular}{lccccc}
\hline & & \multicolumn{4}{c}{ Mean respirable silica exposure $\left(\mathrm{mg} / \mathrm{m}^{3}\right)^{\mathrm{a}}$} \\
\cline { 3 - 6 } Reader & No. of cases & 0.05 & 0.10 & 0.15 & 0.20 \\
\hline 1 & 14 & $0.5(0.2-0.9)$ & $1.2(0.7-2.1)$ & $2.1(1.3-3.6)$ & $3.2(1.8-5.7)$ \\
2 & 24 & $0.6(0.3-1.1)$ & $2.0(1.3-3.0)$ & $3.8(2.6-5.6)$ & $6.1(4.0-9.3)$ \\
3 & 24 & $0.5(0.2-0.9)$ & $1.8(1.1-2.8)$ & $3.9(2.6-5.7)$ & $6.7(4.4-10.0)$ \\
4 & 14 & $0.4(0.2-0.8)$ & $1.1(0.7-2.0)$ & $2.2(1.3-3.8)$ & $3.6(2.0-6.3)$ \\
5 & 7 & $0.1(0.0-0.4)$ & $0.5(0.2-1.1)$ & $1.1(0.5-2.4)$ & $2.1(1.0-4.5)$ \\
& 32 & $0.9(0.6-1.5)$ & $2.7(1.9-3.8)$ & $5.0(3.5-7.0)$ & $7.7(5.3-11.1)$ \\
Any reader & 15 & $0.4(0.2-0.8)$ & $1.2(0.7-2.1)$ & $2.4(1.4-3.9)$ & $3.8(2.2-6.5)$ \\
$\begin{array}{l}\text { Majority } \\
\quad(3 \text { or more) }\end{array}$ & 6 & $0.1(0.0-0.4)$ & $0.4(0.2-1.1)$ & $1.0(0.4-2.2)$ & $1.0(0.4-2.2)$ \\
All readers & & & & &
\end{tabular}

*Estimates of cumulative risk for various levels of respirable silica concentration $\left(\mathrm{mg} / \mathrm{m}^{3}\right)$ based on 40 years of exposure. Results are shown for individual readers, for all cases of silicosis diagnosed by any reader, for cases diagnosed by a majority ( 3 or more) readers, and for those cases where all readers concurred. The last 5 years of dust exposure were excluded. Confidence intervals were calculated by using a Weibull model.

${ }^{a}$ Based on 40 years exposed. 
TABLE IV. Cumulative Respirable Silica Exposure Estimates $\left(\mathrm{mg} / \mathrm{m}^{3}\right.$ years) and $95 \%$ Confidence Intervals for Four Levels of Cumulative Risk (Percent) of Developing Silicosis, by Reader(s)*

\begin{tabular}{|c|c|c|c|c|c|}
\hline \multirow[b]{2}{*}{ Reader } & \multirow{2}{*}{$\begin{array}{c}\text { No. } \\
\text { of cases }\end{array}$} & \multicolumn{4}{|c|}{ Risk } \\
\hline & & $1 \%$ & $2 \%$ & $5 \%$ & $10 \%$ \\
\hline 1 & 14 & $3.5(2.4-5.1)$ & $5.7(3.9-8.4)$ & $11.2(6.8-18.2)$ & $18.6(9.9-35.0)$ \\
\hline 2 & 24 & $2.7(2.0-3.6)$ & $4.1(3.2-5.2)$ & $7.1(5.5-9.1)$ & $10.9(8.1-14.8)$ \\
\hline 3 & 24 & $3.0(2.3-3.9)$ & $4.3(3.4-5.3)$ & $6.9(5.6-8.5)$ & $9.9(7.8-12.7)$ \\
\hline 4 & 14 & $3.7(2.6-5.2)$ & $5.6(4.1-7.7)$ & $9.8(6.7-14.3)$ & $15.1(9.3-24.4)$ \\
\hline 5 & 7 & $5.7(4.0-8.0)$ & $7.8(5.5-11.0)$ & $11.9(7.8-18.3)$ & $16.5(9.7-28.2)$ \\
\hline Any reader & 32 & $2.1(1.6-2.9)$ & $3.3(2.6-4.2)$ & $6.0(4.8-7.5)$ & $9.6(7.3-12.5)$ \\
\hline $\begin{array}{l}\text { Majority } \\
\text { ( } 3 \text { or more) }\end{array}$ & 15 & $3.5(2.5-4.9)$ & $5.4(4.0-7.3)$ & $9.5(6.6-13.6)$ & $14.6(9.3-23.2)$ \\
\hline All readers & 6 & $6.1(4.1-8.9)$ & $8.5(5.6-12.8)$ & $13.2(7.8-22.5)$ & $18.7(9.7-36.1)$ \\
\hline
\end{tabular}

${ }^{*}$ Estimates of cumulative respirable silica exposure $\left(\mathrm{mg} / \mathrm{m}^{3}\right.$ years) with various levels of risk. Corresponding mean silica concentrations may be obtained by dividing by the No. of years of exposure. The last 5 years of exposure were excluded. Confidence intervals were calculated by using a Weibull model. Results are shown for individual readers, for all cases of silicosis diagnosed by any reader, for cases diagnosed by a majority ( 3 or more) readers, and for those cases where all readers concurred.

than 12 months. Any consistent underreporting of high dust levels would also lead to an overestimate of risk as would the restriction of the konimeter method in recording counts higher than 1,000 ppcc.

The most appropriate biological model relating dust exposure to the development of silicosis is uncertain. Exposure during the 5 years preceding the diagnosis was not included in our estimates. A lag period of 2 years was also evaluated, and no significant difference in the two models was evident. It seems unlikely that very recent exposure is relevant to radiographic changes since these represent a slow cellular response to discrete accumulations of dust in the lung. The choice of 2 or 5 years as the lag period is arbitrary but is widely used in the literature. In general terms, it would be anticipated that residence times of dust in the lung are a determinant of the response. On the one hand, it is possible that the longer silica remains in the lung, the more likely it is to cause fibrosis. On the other hand, dust particles are slowly eliminated from the alveoli, and this would have an opposite effect. A timeweighted exposure model was proposed by Jahr [1974] and a more complex method incorporating various dust elimination rates was developed by Berry et al. [1979]. We have used a simple cumulative model at this stage since this is implicit in dust control measures in industries which do not generally take account of the rate or duration of individual worker exposures. One possible source of bias could have arisen in our study if duration of residence time is important. As with many industrial surveys of this type, environmental conditions were much higher in the early years of the industry than in more recent times when efficient ventilation was introduced. These high exposure levels in the early years would be associated with an enhanced effect if multiplied by some function of lung residence time. A risk estimate derived in such circumstances may differ from that obtained in an industry in which dust levels were constant during the survey period. The magnitude of the effect will depend on the biological model which was selected. Unfortunately, it may not be possible to determine from independent evidence which model is most appropriate [Berry et al., 1979]. 
While it is not the responsibility of a research group to identify a particular level of an environmental exposure as being appropriate for control purposes in industry, some interpretive guidelines can be provided. First, it is emphasized that an early stage of radiological abnormality was selected as the end point since this is a stage at which significant disability is unlikely, provided that the condition does not progress. Little information is available about the probability of progression either in miners who leave work or in those who continue in dusty conditions. On pragmatic grounds, it seems likely that the intensity of exposure, and thus, the elapsed time between first exposure and appearance of radiological changes, would be a good prognostic indicator. In most cohort studies, duration of exposure is linked closely to age. The effects of intense exposure were shown in sandblasters [Merewether, 1936; Ziskind et al., 1976] in whom high rates of death due to accelerated silicosis occurred after only 10 or 11 years since the start of exposure. In our series, the age of diagnosis and elapsed time since first exposure in each case was much longer. The details are shown for each case in Table I.

In developing methods to prevent silicosis, two issues are important. The mean population level of dust exposure is clearly the first consideration. A second point concerns the distribution of dust exposure within a given occupational category. Since miners are not randomly employed in all work sites, it would be valuable to study individual dust exposures so that preventive measures can be introduced when appropriate and so that the optimum frequency of sampling can be determined.

In our study, the number of silicosis cases was small, and this was probably the result of low silica exposures in comparison with those previously reported in the literature. This relative paucity of data points and the analytic restrictions in cohorts where most of the exposures are low present an interesting contrast with the problems often encountered in studies associated with high response rates. In this last situation, it is usually necessary to extrapolate beyond the data points in order to estimate risks at low levels of exposure.

\section{ACKNOWLEDGMENTS}

The investigation was funded by the Ontario Mining Association, the Ministry of Labour of the Government of Ontario, and the Workers' Compensation Board of Ontario. Our thanks are due to these agencies and for the support of the members of the steering committee.

Special acknowledgment is made to miners who participated in the investigations, to mine management, and to representatives of the United Steel Workers of America and the Union of Mine Mill and Smelter Workers at the mines where the investigations took place.

A large number of chest radiographs were classified by Drs. J. Chan, J. Roos, W. Maehle, and W. K. C. Morgan, to whom we express our great thanks.

\section{REFERENCES}

Ashe HB, Bergstrom DE (1964): Twenty-six years' experience with dust control in the Vermont granite industry. Ind Med Surg 33:73-78.

Ayer HE, Dement JM, Busch KA, Ashe HB, Levadie BTH, Burgess WA, DiBerardinis, L (1973): A monumental study. Reconstruction of a 1920 granite shed. Am Ind Hyg Assoc J 34:206-211.

Beadle DG (1967): An epidemiological study of the relationship between the amount of dust breathed and the incidence of silicosis in South African gold miners. In Davies CN (ed): "Inhaled Particles and Vapours, II.” Oxford: Pergamon Press, pp 479-492. 
Berry G, Gilson JC, Holmes S, Lewinsohn HC, Roach SA (1979): Asbestosis: A study of dose-response relationships in an asbestos textile factory. Br J Ind Med 36:98-112.

Cooper WC, Cralley LJ (1958): "Pneumoconiosis in diatomite mining and processing (Public Health Service Publication No. 601).” Washington, DC: US Dept. of Health Education and Welfare, Occupational Health Program.

Finkelstein MM (1985): A study of dose-response relationships for asbestos associated disease. Br J Ind Med 42:319-325.

Fox AJ, Greenberg M, Ritchie GL, Barraclough, RNJ (1975): "A survey of respiratory disease in the pottery industry." London: H.M. Stationery Office.

Fulton WB, Butters FE, Dooley AE, Koppenhaver FB, Matthews JL, Kirk RM (1939): “A study of silicosis in the silica brick industry." Harrisburg: Commonwealth of Pennsylvania, Dept. of Health, Bureau of Industrial Hygiene.

Gardner LU (1938): Etiology of pneumoconiosis. JAMA 111:1925-36.

International Labour Office (1972): "ILO U/C International Classification of Radiographs of Pneumoconioses 1971. Occupational Safety and Health Services, No. 22 (Rev. 71)." Geneva: International Labour Office.

International Labour Office (1980): "Guidelines for the use of ILO International Classification of Radiographs of Pneumoconioses. Rev. Ed. 1980. Occupational Safety and Health Services, No. 22 (Rev)." Geneva: International Labour Office.

Jahr J (1974): Dose-response basis for setting a quartz threshold limit value: A new, simple formula for calculating the "lifetime dose" of quartz. Arch Environ Health 29:338-340.

Kaplan EL, Meier, P (1958): Nonparametric estimation from incomplete observations. J Am Stat Assoc 53:457-481.

King EJ, Mohanty GP, Harrison CV, Nagelschmidt G (1953a): The action of different forms of pure silica on the lungs of rats. Br J Ind Med 10:9-17.

King EJ, Mohanty GP, Harrison CV, Nagelschmidt G (1953b): The action of flint of variable size injected at constant weight and constant surface into the lungs of rats. Br J Ind Med 10:76-92.

Lawless JF (1982): "Statistical Models and Methods for Lifetime Data." New York: John Wiley \& Sons, pp 15-24.

Merewether ERA (1936): The risk of silicosis in sand-blasters. Tubercle 17:385-391.

Muir DCF, Shannon HS, Julian JA, Verma DK, Sebestyen A, Bernholz CD (1989): Silica exposure and silicosis among Ontario hardrock miners: I. Methodology. Am J Ind Med 16:5-11.

Nelson W (1982): “Applied Life Data Analysis.” New York: John Wiley \& Sons, pp 346, 347.

Rajhans GS, Budlovsky J (1972): Dust conditions in brick plants of Ontario. Am Ind Hyg Assoc J 33:258268.

Russell AE, Britten RH, Thompson LR, Bloomfield JJ (1929): "The health of workers in dusty trades-II. Exposure to siliceous dust (granite industry)" (Public Health Bulletin No. 187). Washington, DC: US Treasury Dept., Public Health Service.

Thériault GP, Burgess WA, DiBerardinis, LJ, Peters JM (1974a): Dust exposure in the Vermont granite sheds. Arch Environ Health 28: 12-17.

Thériault GP, Peters JM, Johnson WM (1974b): Pulmonary function and roentgenographic changes in granite dust exposure. Arch Environ Health 28:23-27.

Verma DK, Sebestyen A, Julian JA, Schmidt H, Bernholz CD, Shannon HS, Muir DCF (1989): Silica exposure and silicosis among Ontario hardrock miners: II. Exposure estimates. Am J Ind Med 16:13-29.

Walton WH, Dodgson J, Hadden GG, Jacobsen M (1977): The effect of quartz and other non-coal dusts in coalworkers' pneumoconiosis. Part I: Epidemiological studies. In Walton WH, McGovern B (eds): "Inhaled Particles IV (II)." Oxford: Pergamon Press, pp 669-690.

Ziskind M, Weill H, Anderson AE, Samimi B, Neilson A, Waggenspack C (1976): Silicosis in shipyard sandblasters. Environ Res $11: 237-243$. 